\section{Challenges in Scientific Writing}

One of the major obstacles that most physicians and scientists face when conducting clinical research is writing of the manuscripts in a manner that is acceptable by the journals. Putting their work on paper can be a challenging task. There are various challenges faced - the actual language, the standard design that must be followed, referencing, etc., Here, we discuss few of the common challenges faced and their solutions.

\section{Scientific Writing is a Struggle that Everyone Faces (At First)}

The structure of a scientific manuscript is different from other forms of writing. It is not an easy task to learn and master and usually takes time. There are other challenges too such as analysis of the data and citations. Identifying one's unique contribution to the literature can also come across as challenging, given all the research work that has already been done in the past. However, greatest improvements come only with practice.

\section{Language and Grammatical Inaccuracies}

Too many grammatical errors make it difficult to assess the content of a manuscript. Seeking support from a writing expert can help learn and edit one's own work. Getting one's idea across the reader is of utmost importance, and grammatical errors may send across the wrong or unclear message.

- Spell check: A great piece of writing can be easily ruined by spelling mistakes. These can easily be avoided using a few strategies. Spellcheck can prove to be handy tool. Remember to choose the correct language (e.g. US/American English or UK/British English) for your target journal or thesis guidelines. Setting the spellchecker in MS word to English is something not everyone does. But, one must not rely on these tools. Proof-reading the manuscript multiple times is the best way to avoid these mistakes. Proof-reading one's article backwards, from finish to start, is a very effective way to combat common mistakes. Also, one must be on a look out for homophones. Homophones are words that are spelt differently and have different meanings, but sound the same, for example, "their" and "there." Be careful with words with double letters. Other common errors are its vs. it's, accept vs. except, and loose vs. lose

- Phrases that can be replaced by one word: For example, "On the other hand,..." (4 words) can be replaced by "However,..." (1 word); "During the course of, in the course of" - can be replaced by "during" or "in." Very long and complex sentences, which are almost always hard for the reader to understand, can usually be divided into two simpler sentences
- Word usage: It is important to choose precise words with unmistakable meanings. Use standard words in their established meanings, especially for the benefit of foreign readers

- Using abbreviations: All abbreviations must be defined in full when used for the first time in the abstract of the article. They must be defined again at their first use in the main paper.

Here are a few examples of common mistakes encountered:

- Compare with, compare to - compare with means to examine similarities and differences and compare to means to represent as similar

- It should be pointed out, noted, mentioned, emphasized, etc., - such preambles almost always add nothing but just words. Instead, directly stating what needs to be said is the way to go

- Apparently (apparent) - means obviously or plainly evident, but it also means seemingly as well as observably. The writer is clear about their intention, but readers may not be. Ambiguity results. Use obvious (ly), clear (ly), seeming (ly), evident (ly), observable or observably, to clear all doubt

- Etc. - Use at least two items or illustrations before "and so forth" or "etc."

\section{Inaccurate English Terminologies}

The information presented in scientific publications must be accurate. When a phrase is repeatedly published in a certain manner, it does not make it correct.

Here are a few examples:

- The term "Cancer genes" is commonly used in articles to describe genes that, when mutated, cause cancer. However, the accurate terminology here would be "Cancer-mutated genes." The gene mutations actually cause the cancer, and not the genes

- A commonly used terminology "Hodgkin's Lymphoma" is actually incorrect. The accurate terminology would be "Hodgkin Lymphoma"

- Another example is the use of the term "risk." The correct and accurate term is "harm." When a patient is to receive a computed tomography scan, it is not accurate to quote "the potential risk" of radiation exposure. The exposure is certain. Instead, the potential "harm" is what needs to be focused on.

\section{Approach Criticism Objectively}

Science only improves through critical review. Getting the write up reviewed by peers and accepting criticism only helps improve the work toward building a stronger manuscript. 


\section{Plagiarism}

It is very difficult to integrate researched text into one's own style of writing, and it is also something that may be affected by one's level of proficiency in English. One important skill that is very difficult to master is paraphrasing. It takes ongoing commitment and practice to be competent in. Strategies to combat this shall be discussed in the subsequent issues of this journal.

\section{Referencing}

Another common challenge faced in scientific writing is referencing. The format used for referencing must be consistent. Referencing systems such as APA and Refworks must be used to avoid these errors and inconsistencies. These systems take time to master.

Overall, scientific writing is a challenging task without mastering which one's own research work cannot reach the journals to be published. The basics of each section of a manuscript shall be discussed in detail in the subsequent issues of this journal.

\section{Amrita Prayag}

Deenanath Mangeshkar Hospital and Research Centre, Pune, Maharashtra, India
Address for correspondence: Dr. Amrita Prayag, Deenanath Mangeshkar Hospital and Research Centre, Pune - 411 004, Maharashtra, India. E-mail: medamrita@gmail.com

Submitted: 28-Dec-2019 Accepted in Revised Form: 02-Jan-2020

Published: 17-Feb-2020

This is an open access journal, and articles are distributed under the terms of the Creative Commons Attribution-NonCommercial-ShareAlike 4.0 License, which allows others to remix, tweak, and build upon the work non-commercially, as long as appropriate credit is given and the new creations are licensed under the identical terms.

\begin{tabular}{|l|l|}
\hline \multicolumn{2}{|c|}{ Access this article online } \\
\hline Quick Response Code: & Website: \\
\hline & www.ijmpo.org \\
\cline { 2 - 3 } & DOl: \\
\hline
\end{tabular}

How to cite this article: Prayag A. Challenges in scientific writing. Indian J Med Paediatr Oncol 2019;40:554-5. 